\title{
Study of photovoltaic systems using modelling and simulation
}

\author{
Aurelian Nicola ${ }^{1}$, Cosmin Vitan ${ }^{1 *}$, Cristian Aron ${ }^{1}$, Daniel Matei ${ }^{1}$, and Ionela Grecea ${ }^{1}$ \\ ${ }^{1}$ University of Petrosani, 20 University street, 332006, Petrosani, Romania
}

\begin{abstract}
The article presents mathematical models and simulation programs, made in MATLAB - Simulink, of the main components within photovoltaic system. For the continuous supply of electricity to consumers, in addition to photovoltaic panels are used electric accumulators and static converters, which have the role of converting direct current into alternating current or alternating current into direct current and to monitor and control the charging-discharge batteries process. The assembly consisting of all the elements presented above, interconnected and dimensioned to operate in a single system, is modelled and simulated and the results obtained reflect the limits but especially offers the possibility of choosing the optimal solution for a park of energy production based on solar radiation.
\end{abstract}

\section{Introduction}

For continuous supply of electricity to consumers, in addition to photovoltaic panels are used electric accumulators and static converters (which have the role of transforming direct current into alternating current or direct current into direct current) and monitor and control process of charging/ discharging batteries. The assembly consisting of all elements presented above, interconnected and dimensioned in order to operate in a single system, forms a photovoltaic system.

Auxiliary power sources are often used to avoid oversizing photovoltaic systems.

Photovoltaic systems can be divided into two categories: autonomous photovoltaic systems and grid-connected photovoltaic systems.

Figures 1.a. - 1.b. show the two categories of photovoltaic systems. Autonomous photovoltaic systems are divided into two categories: autonomous photovoltaic systems without energy storage and autonomous photovoltaic systems with energy storage.

In order to meet electricity needs of consumers, photovoltaic panels can be connected in series, parallel or series-parallel. The accumulators in composition of a photovoltaic system can be connected in series, parallel or series-parallel, in order to obtain an optimal voltage and current intensity.

\footnotetext{
*Cosmin Vitan :vitan.daniel.cosmin@gmail.com
} 

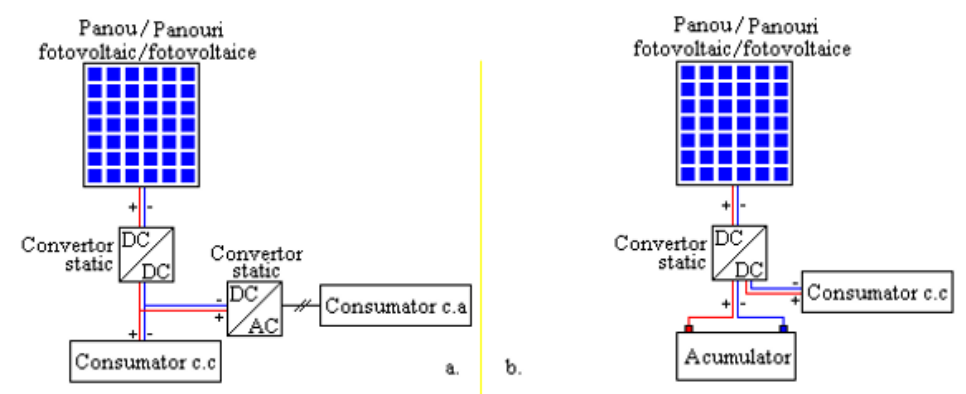

Fig. 1. Autonomous photovoltaic systems (SFA) - a. without energy storage; b. with energy storage.

\subsection{MATLAB - Simulink simulation of a photovoltaic panel}

The mathematical model underlying MATLAB - Simulink program for simulating a photovoltaic panel is detailed in the article M.S. Nan (2019) [1, 2].

Photovoltaic panel chosen to exemplify the simulation is TS-M400 panel [3]. In order to run program $[4,5]$, following settings are made: parameters of TS-M400 photovoltaic panel are introduced [3]; simulation interval is $t \epsilon\left[t_{0} \ldots t_{f}\right]=\left[0 \ldots U_{O C}\right]$; integration method is Dorman - Prince of order 4/5; relative error of integration method $\varepsilon_{r}=10^{-7}$ and absolute error of integration method $\varepsilon_{a}=10^{-7}$. Results obtained after simulation are presented in Figure 2.
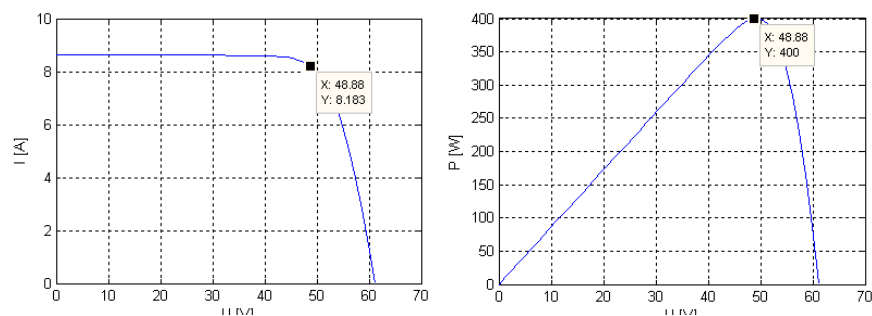

Fig. 2. The characteristic of current-voltage and power-voltage pairs of the TS-M400 panel.

Following the analysis of power - voltage characteristic, Figure 2, it is observed that maximum point is: $\left(U_{\max }, P_{\max }\right) \approx(49 \mathrm{~V}, 400 \mathrm{~W})$. On the other hand, it is observed that maximum value of current intensity, corresponding to maximum voltage $U_{\max }$, is $I_{\max } \approx 8.1 \mathrm{~A}$. Maximum values of current, voltage and power, obtained from simulation, coincide with values in technical documentation of photovoltaic panel TS-M400 [2].

\subsection{Simulation in MATLAB - Simulink of an electricity rechargeable battery}

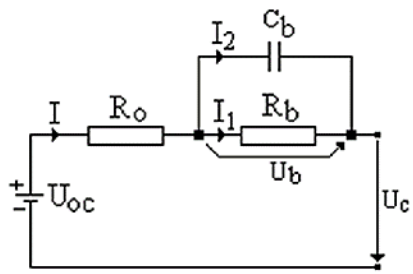

Fig. 3. Thevenin's equivalent scheme for rechargeable battery. 
The batteries have role of storing the electricity supplied by photovoltaic panels, this are able to be discharged and charged several times (rechargeable batteries). Modelling and simulation of a battery, in this paper, is based on Thevenin's equivalent scheme (Figure 3).

$$
\begin{gathered}
U_{b}(s)=\frac{R_{b}}{1+T_{a} \cdot s} \cdot I(s) \\
U_{c}(s)=U_{o c}(s)-U_{b}(s)-R_{0} \cdot I(s) \\
P=\frac{U_{b}^{2}}{R_{b}}+R_{0} \cdot I^{2}
\end{gathered}
$$

Based on above relationships, a simulation program was performed in MATLABSimulink [2, 4], for rechargeable battery, Figure 4.
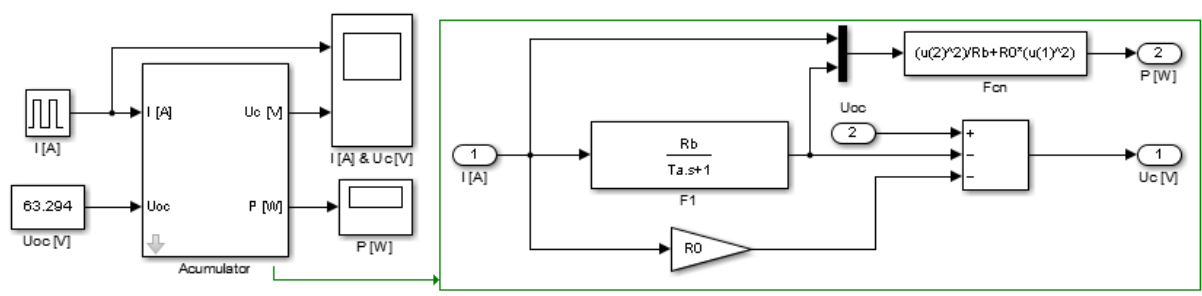

Fig. 4. MATLAB - Simulink simulation program of an electric rechargeable battery.

Rechargeable battery analysed by simulation is of $\mathrm{LiMn}_{2} \mathrm{O}_{4}$ type [6, 7], having a nominal voltage of $57.6 \mathrm{~V}$ and a nominal capacity of $100 \mathrm{Ah}$. The parameters that define mathematical model of $\mathrm{LiMn}_{2} \mathrm{O}_{4}$ rechargeable battery are presented in table 1 .

Table 1. Parameters of mathematical model to $\mathrm{LiMn}_{2} \mathrm{O}_{4}$ rechargeable battery.

\begin{tabular}{|c|c|c|c|c|}
\hline Battery type & $\mathbf{U}_{\text {oc }}[\mathbf{V}]$ & $\mathbf{C}_{\mathbf{b}}[\mathbf{F}]$ & $\mathbf{R}_{\mathbf{b}}[\mathbf{\Omega}]$ & $\mathbf{R}_{\mathbf{0}}[\mathbf{\Omega}]$ \\
\hline $\mathbf{L i M n}_{\mathbf{2}} \mathbf{O}_{4}$ & 63.294 & 4581 & 0.00736 & 0.02423 \\
\hline
\end{tabular}

In order to run program from Figure 4, with MATLAB - Simulink, following settings are made: battery parameters are entered, table 1 ; simulation interval is $t \epsilon\left[t_{0} \ldots t_{f}\right]=$ [0...1000]; integration method is: Dorman - Prince of order 4/5; relative error of integration method $\varepsilon_{r}=10^{-7}$ and absolute error of integration method $\varepsilon_{a}=10^{-7}$. Results obtained from simulation are presented in following figures (Figures 5 and 6).

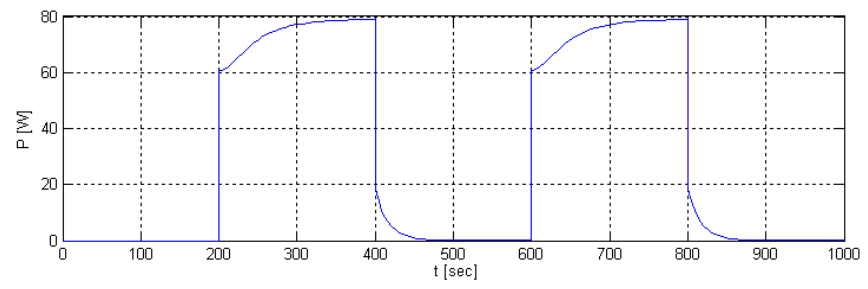

Fig. 5. Loss of electrical power over time. 

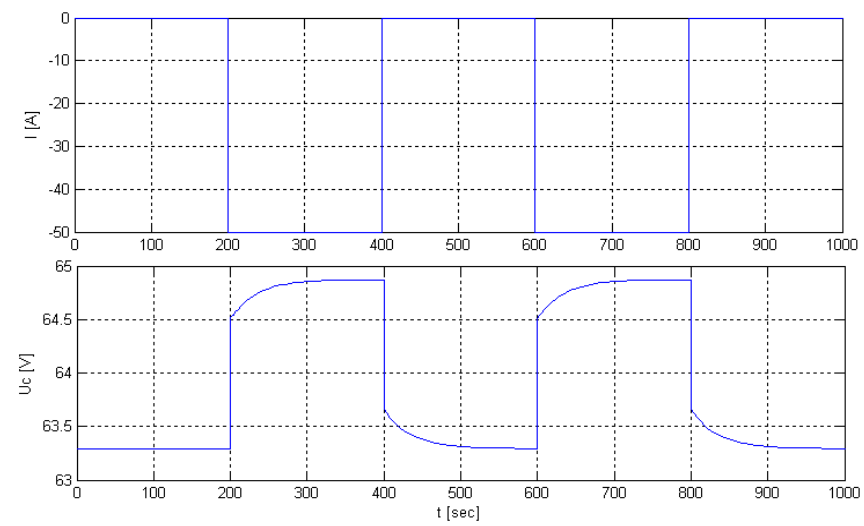

Fig. 6. Variation of current and voltage in relation to time - for battery discharge.

From figures 5 and 6 , it is observed that between time moments $t_{1} \epsilon[200,400] \mathrm{s}$ and $t_{2} \epsilon[600,800] \mathrm{s}$, an electricity consumer appears at rechargeable battery terminals, this being highlighted by discharge of battery, to $I=50 \mathrm{~A}$, as well as by losses of electrical power that reach values of approximately $P=78,8 \mathrm{~W}$.

Figure 4 shows that input vector of simulation block consists of charging/ discharging current and the open circuit voltage of rechargeable battery. From Figure 5, it is observed that at appearance of a current pulse to $I=50 \mathrm{~A}$ between time moments presented above, voltage at rechargeable battery terminals decreases, reaching a value of approximately $U_{c}=61.72 \mathrm{~V}$, which means a discharge of rechargeable battery. On the other hand, in case of a current pulse to $I=-50 \mathrm{~A}$, between moments of time presented above, voltage at battery terminals increases, reaching a value of approximately $U_{c}=64.87 \mathrm{~V}$, which means a rechargeable battery charge, Figure 6.

\subsection{MATLAB - Simulink simulation of static converters}

Electrical energy produced by a photovoltaic panel has a variable character in time due to several factors, among which we mention: alternation day/ night, alternation of clear sky/ overcast sky, etc. The systems through which energy flow is conditioned in photovoltaic systems are called static converters [8,9]. In addition to function of conditioning flow of electricity, static converters in composition of photovoltaic systems also fulfil role of monitoring and control to process of charging/ discharging rechargeable batteries.

DC-DC converters are of two types: step-up dc-dc converter voltage (boost) converters and step-down (buck).

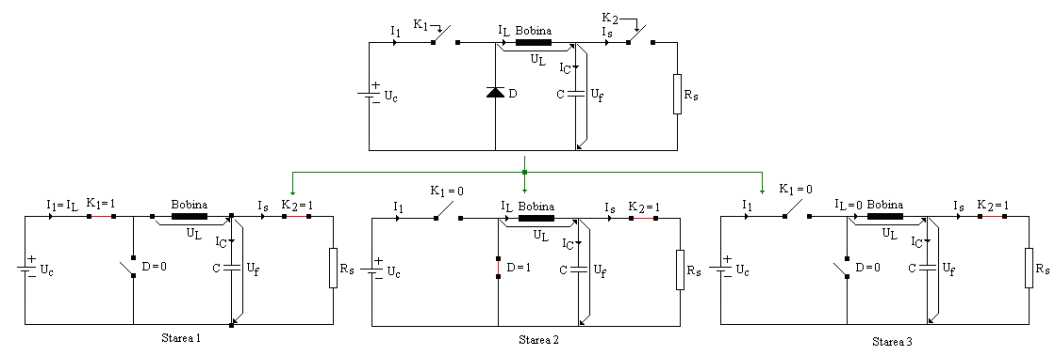

Fig. 7. Principle of operation to buck-type dc-dc converter.

In order to determine equations underlying mathematical model of buck-type dc-dc converter, mode of operation that is determined by three states, is shown Figure 7. 
Applying Kirchhoff's theorems, in circuits from Figure 7, we obtain the following equations:

$$
\begin{gathered}
I_{L}=I_{s}+I_{c} \\
I_{c}=C \cdot \frac{d U_{f}}{d t} \\
U_{L}=\left(U_{C}-U_{f}\right) \cdot K_{1}-U_{f} \cdot \overline{K_{1}} \cdot \operatorname{sign}\left(I_{L}\right) \\
U_{L}=L \cdot \frac{d I_{L}}{d t}
\end{gathered}
$$

Under these conditions, equations $1 \ldots 4$, define mathematical model of dc-dc converter (buck type) and simulation program in MATLAB - Simulink, is based on these equations and is presented in Figure 8.

The control of transistor (static switch) from dc-dc converter component, is made by PWM (Pulse Width Modulation) technique.

In order to control (regulate) voltage at consumer terminals, a regulation system (SRA) is used in which execution element is dc-dc converter and technological process is represented by electricity consumers.

The voltage transducer was not taken into account in simulation because voltage transducer was considered a proportional element defined by a unit proportionality constant.

The automatic regulator chosen, in order to control voltage at consumer terminals, is a PI type regulator (Integral Proportional) and the transfer function is given by relation:

$$
G_{R}(s)=\frac{Y_{c}(s)}{E(s)}=K_{R} \cdot\left(1+\frac{1}{T_{R} \cdot s}\right)
$$

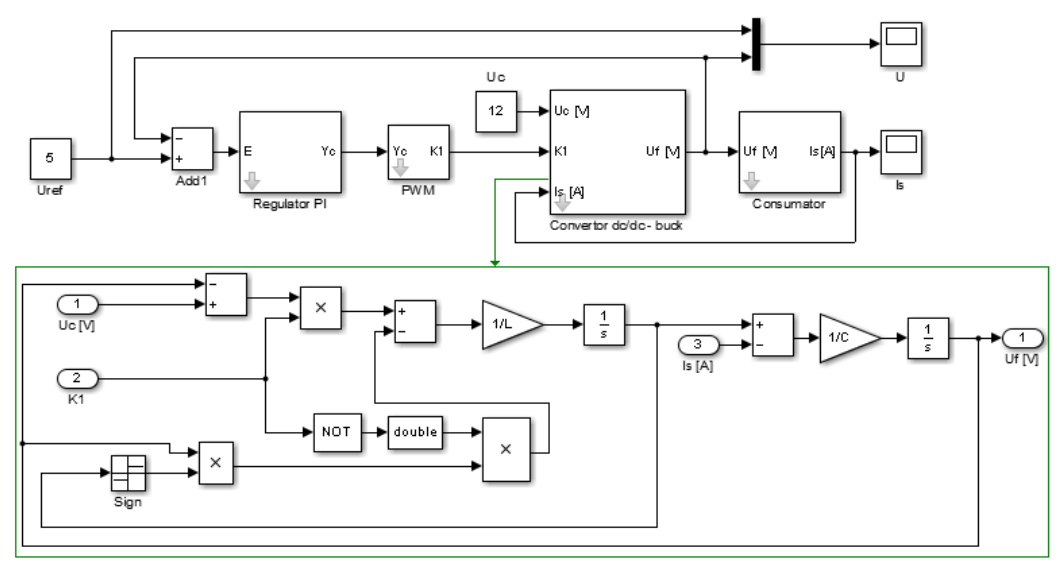

Fig. 8. MATLAB-Simulink simulation program of buck-type dc-dc converter.

In order to highlight results obtained after running program from Figure 8, we will design a dc-dc converter (buck type) defined by following parameters: $U_{c}=55 \mathrm{~V} ; U_{f}=30 \mathrm{~V} ; I_{s}$ $\max =111 \mathrm{~A}$ (maximum current required by consumer); $f_{c}=5000 \mathrm{~Hz}$ (pulses frequency of 
$\mathrm{PWM}$ ); $\Delta U_{f}=0.3 \mathrm{~V} ; \mathrm{L}=1239.6 \mu \mathrm{H} ; C_{\min }=183.3 \mu \mathrm{F} ; R_{s c}=0.13 \Omega$ (equivalent series resistance of capacitor); $C=200 \mu F ; R_{s}=4 \Omega$ (load resistance for consumer); $K_{R}=0.001$ (proportionality constant of regulator); $T_{R}=0.0005 \mathrm{~s}$ (regulator integration time constant).

In order to run, with MATLAB - Simulink program $[2,4]$, following settings are made: parameters are entered; simulation interval is $t \epsilon\left[t_{0}, t_{f}\right]=[0,0.2]$; integration method is: Dorman - Prince of order 4/5; relative error of integration method $\varepsilon_{r}=10^{-7}$; absolute error of integration method $\varepsilon_{a}=10^{-7}$.

Results obtained after running simulation program, under conditions presented above, are presented in Figure 9.

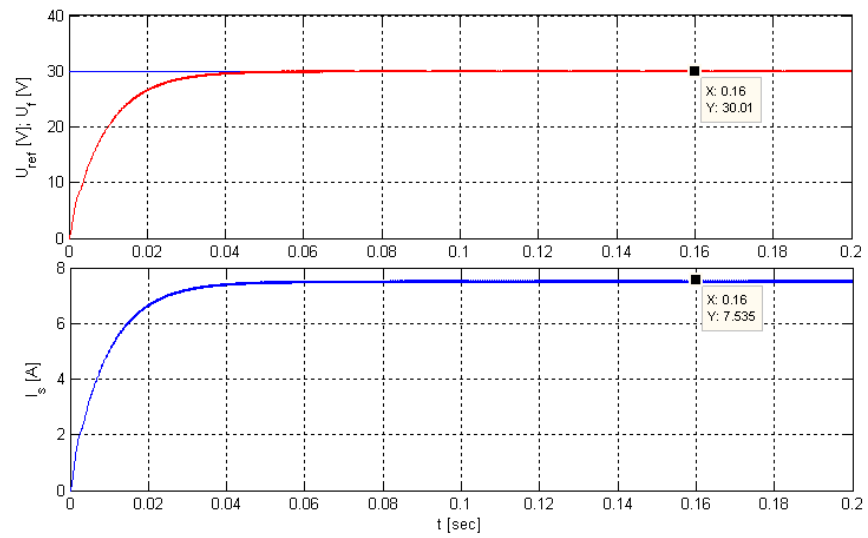

Fig. 9. Time variation of voltage at consumer terminals in tandem with time variation of load current.

From obtained results it is observed that the control system has a very good dynamic. Voltage oscillations at consumer terminals may decrease with increasing capacitor capacitance or transistor chipping frequency.

In order to determine equations underlying the mathematical model of boost-type dc-dc converter, we will proceed in same way as in case of buck-type dc-dc converter.

\section{Modelling and simulation in MATLAB - Simulink of a photovoltaic system}

For example, in following we will present simulation programs of two photovoltaic systems $[2,4],[10-13]$. The first photovoltaic system analysed is an autonomous type, without energy storage, in which the consumer is three-phase alternating current Figure 10.

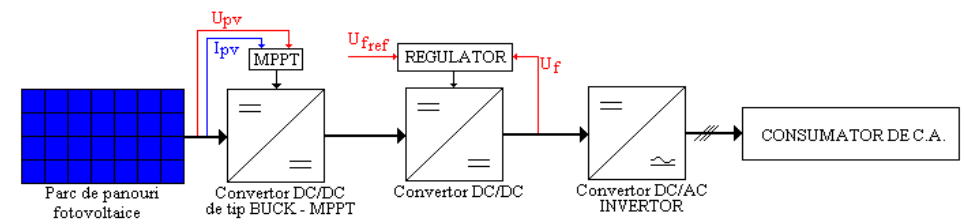

Fig. 10. Autonomous photovoltaic system without energy storage and alternating current consumer.

Photovoltaic system is formed around a photovoltaic park, made of 400 photovoltaic panels type TS-M400. The panels in photovoltaic panel are connected in series - parallel (10 parallel columns of 40 photovoltaic panels connected in series), so voltage generated is 40 times higher and current is 10 times higher than in case of a single TS-M400 panel. Maximum power of photovoltaic park is 400 times higher than the power of photovoltaic panel TS-M400 (maximum power is $P_{s f}=160 \mathrm{~kW}$ ). 
The current - voltage and power - voltage characteristics of photovoltaic park are presented in Figure 11.

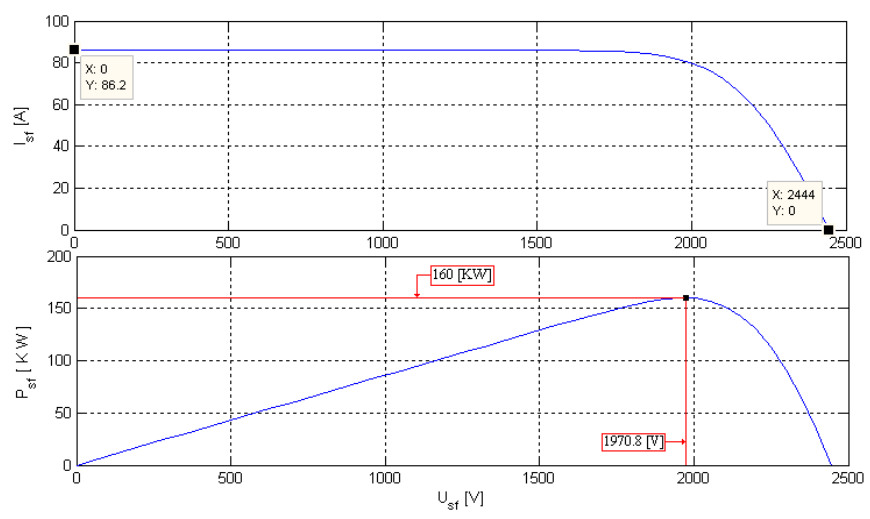

Fig. 11. Characteristic of current - voltage and power - voltage for photovoltaic system.

From analysis of Figure 11, it is observed that maximum power of $P_{s f}=160 \mathrm{~kW}$, is obtained at a maximum voltage of $U_{s f_{-} \max }=1970.8 \mathrm{~V}$ and a maximum current of $I_{s f_{\max }}=81.2 \mathrm{~A}$. Results presented were obtained at an intensity of solar radiation of 1000 $\mathrm{W} / \mathrm{m}^{2}$ and a temperature of $+25^{\circ} \mathrm{C}$, and alternating current consumer is a three - phase RL load defined by following parameters: $R=7 \Omega$ and $L=2 \mathrm{mH}$.

To follow maximum power point, we will use a buck-type dc-dc converter in which the transistor of converter is controlled based on PO (Disturb - Observe) algorithm and implement PO algorithm, we will use measured values of current and voltage generated by photovoltaic park.

In order to filter voltage, from input of MPPT converter (buck type) we will use a capacitive filter defined by following value $C_{I}=1000 \mu \mathrm{F}$ and parameters, that define MPPT converter of buck type, this are: $L=6.73 \mathrm{mH}$ and $C_{2}=400 \mu \mathrm{F}$. The chipping frequency of transistor in the component of MPPT converter, of buck type, is: $f_{c}=5 \mathrm{kHz}$.

To control DC voltage from input of three-phase inverter to bridge, a buck-type dc-dc converter is used and parameters that define this converter are: $L=1.36 \mathrm{mH}$ and $C=800 \mu \mathrm{F}$. Chipping frequency of transistor dc-dc converter, buck type, is: $f_{c}=10 \mathrm{kHz}$.

Parameters that define automatic PI type regulator, from dc-dc converter are: $K_{R}=100$, $K_{I}=0,009$ and reference voltage (the desired voltage at input of three-phase inverter), is $U_{c_{-} \text {ref }}=500 \mathrm{~V}$.

Modulation index, used in control of six transistors in three-phase inverter component in bridge is $m=0.8776$ and chipping frequency is $f_{c}=10 \mathrm{kHz}$.

Photovoltaic system simulation program was developed in MATLAB - Simulink and takes into account specifications presented above. Simulation program of autonomous photovoltaic system, without energy storage, is presented in Figure 12.

In order to run, with MATLAB - Simulink program, following settings are made: parameters are entered; simulation interval is $t \epsilon\left[t_{0}, t f\right]=[0,0.15]$; integration method is: Dorman - Prince of order 4/5; relative error of integration method $\varepsilon_{r}=10^{-7}$; absolute error of integration method $\varepsilon_{a}=10^{-7}$. 


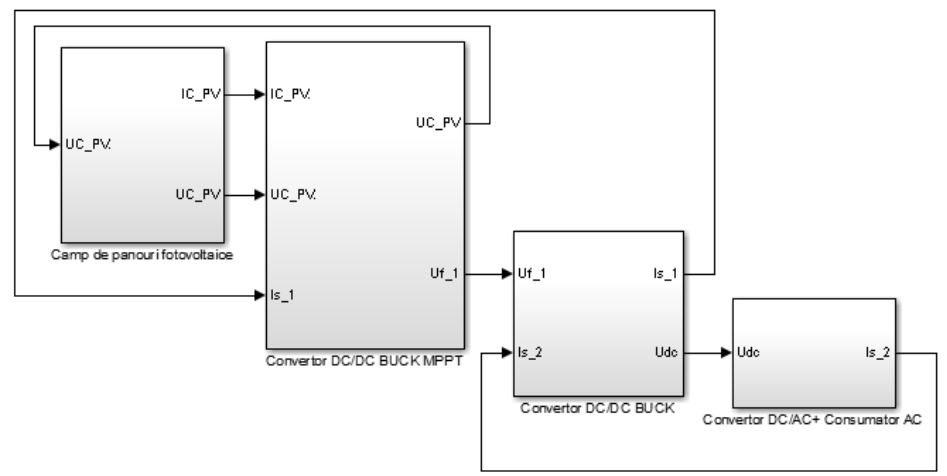

Fig. 12. Simulation program, in MATLAB - Simulink, of an autonomous photovoltaic system, without energy storage.

The main results obtained, following running of simulation program from Figure 12, under conditions presented above, are presented in Fgure13.

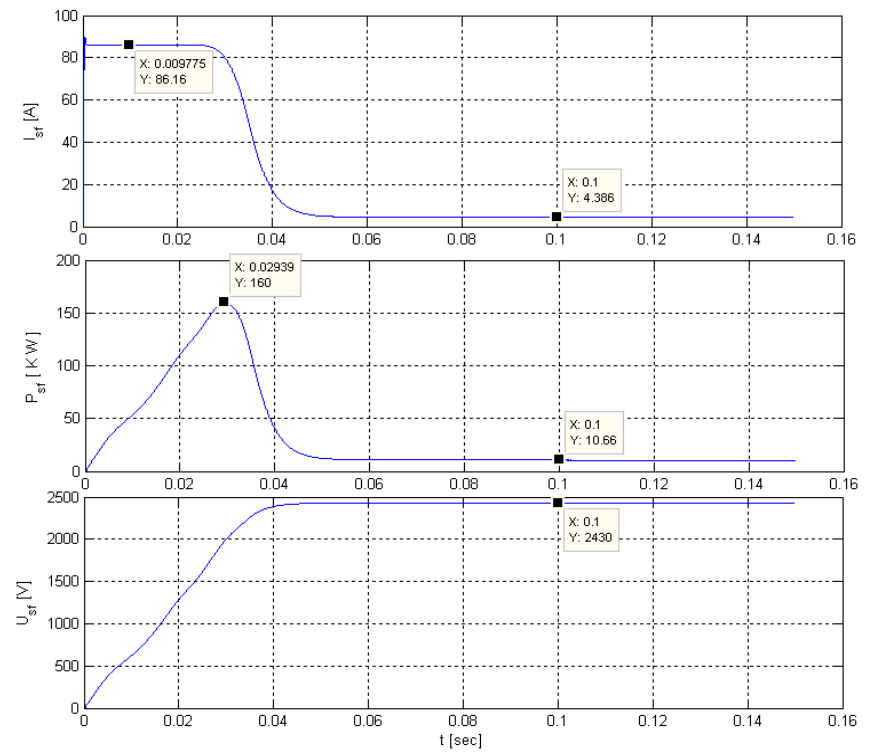

Fig. 13. Time variation of current, power and voltage at terminals of photovoltaic park.

From analysis of graph in Figure 13, it is observed that MPPT regulator in tandem with dc-dc converter, of buck type, regulates maximum power point according to power required by consumer. Maximum power point is defined by following values: $U_{p t}=2430 \mathrm{~V}$, $I_{p t}=4.386 A$ and $\mathrm{P}_{\mathrm{p} t} \approx 10.66 \mathrm{~kW}$.

The second photovoltaic system analysed is an autonomous type, with energy storage, in which the consumer is direct current Figure 14. 


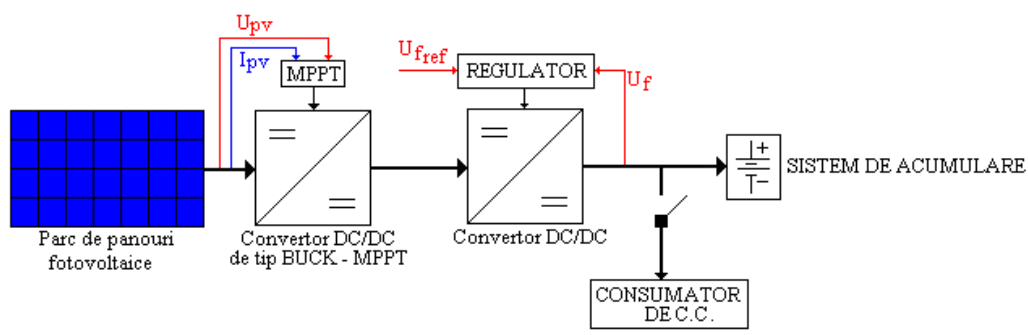

Fig. 14. Autonomous photovoltaic system with direct current energy storage.

In DC consumer simulation, it is a resistive load characterized by following resistance value: $R=5 \Omega$. Electricity storage system is made with help of 8 batteries, type $\mathrm{LiMn}_{2} \mathrm{O}_{4}$, connected in series, in these conditions, voltage at terminals of storage system is 8 times higher than voltage of a single battery. The other elements in composition of photovoltaic system are identical to those in first photovoltaic system analysed and simulation conditions remain the same.

During simulation, DC consumer is connected to terminals of energy storage system for a period of time at $0.8 \mathrm{~s}$ after which it is disconnected.

The simulation program, in MATLAB - Simulink, of photovoltaic system with energy storage, is presented in Figure 15, and main results of simulation are illustrated in Figures 16 and 17, where is presented variation in time of current, power and voltage generated by the park of photovoltaic panels.

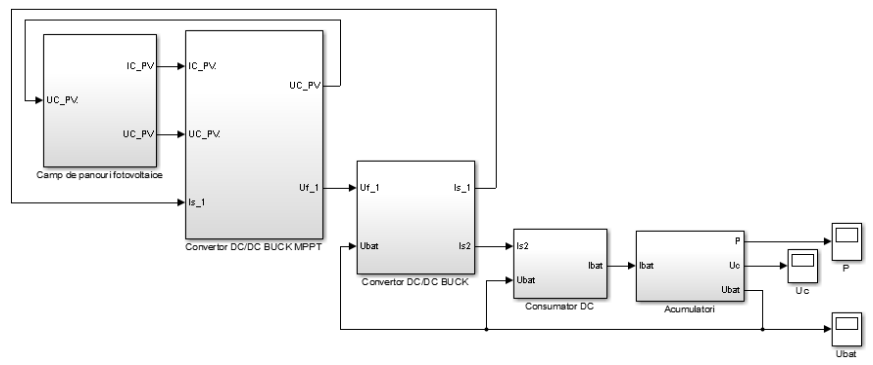

Fig. 15. Simulation program in MATLAB - Simulink of photovoltaic system with energy storage.

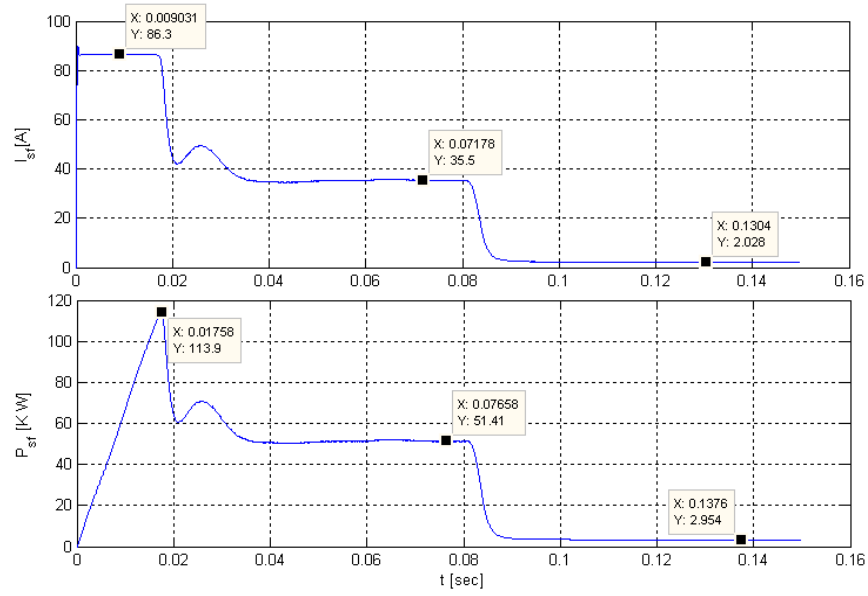

Fig. 16. Time variation of current and electric power generated by photovoltaic panel park. 


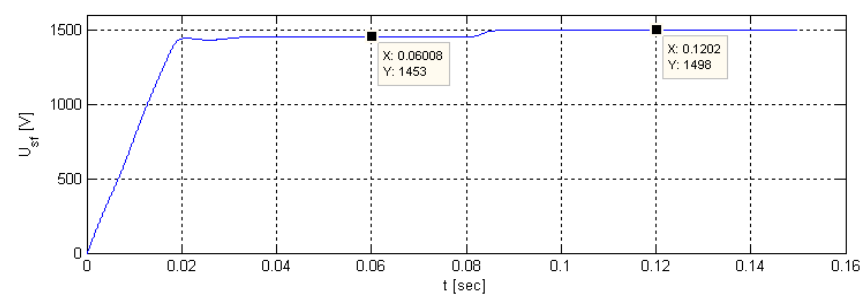

Fig. 17. Time variation of voltage generated by photovoltaic panel park.

Following the analysis of graphs presented above, it is observed that we have two points of maximum power, defined by the following values:

- point 1: $U_{p t}=1453 \mathrm{~V} ; I_{p t}=33.5 \mathrm{~A}$ and $P_{p t} \approx 51.41 \mathrm{~kW}$;

- point 2: $U_{p t}=1498 \mathrm{~V} ; I_{p t}=2.02 \mathrm{~A}$ and $P_{p t} \approx 2.954 \mathrm{~kW}$.

The two points are set by MPPT controller, depending on power required for load.

In Figure 18, time variation of current is presented, specific to electricity storage system.
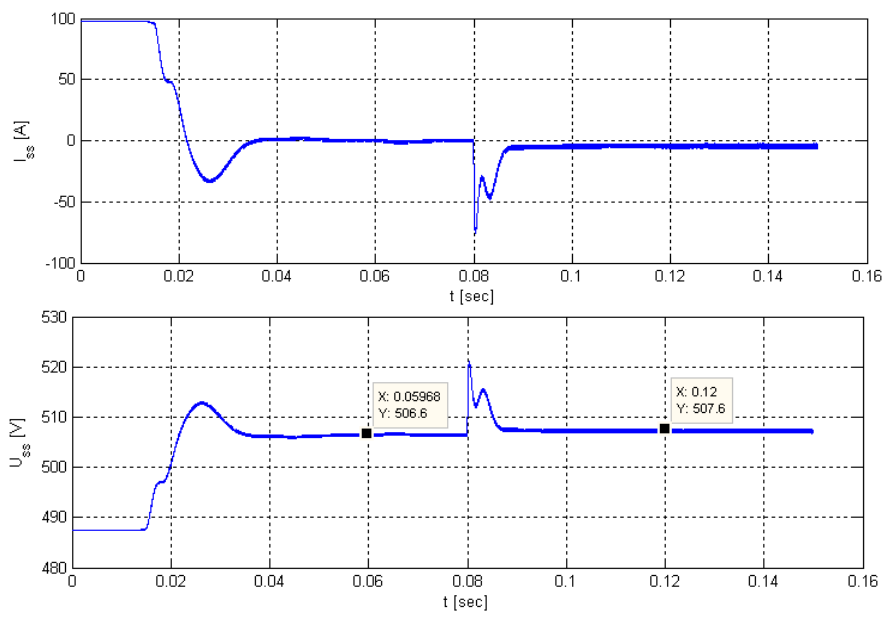

Fig. 18. Time variation of current and voltage in energy storage system.

It is known that when current through battery has a positive value, battery is discharged, and when it has a negative value, battery is charged. Taking into account observation presented above, in Figure 18, it is observed that when resistive load is connected, current in storage system increases to a maximum value of $100 \mathrm{~A}$ for a time of $0.015 \mathrm{~s}$, during which time storage system discharges. This is noticed by MPPT regulator, as well as by PI regulator, from composition of the two dc-dc converters, of buck type, so that, after a transient time of approximately $0.02 \mathrm{~s}$, photovoltaic system compensates electricity consumption, so that current through the storage system it becomes null (the storage system is neither loaded nor unloaded).

At moment of disconnection, resistive load, current through the storage system, changes its direction, so that storage system is charged (current varies around values of $-5 A$, in steady state). It can also be seen that when resistive load is connected, voltage at terminals of storage system is approximately $487.4 \mathrm{~V}$, which means that the storage system at initial moment is at a capacity of $96 \%$. From moment the resistive load appears at terminals of storage system, for a time of about $0.015 \mathrm{~s}$, voltage at terminals starts to decrease (there is an insignificant voltage drop), after which control systems intervene in process and regulate voltage to about $506.6 \mathrm{~V}$. On the other hand, it is observed that when resistive load is 
switched off, voltage at terminals increases and stabilizes after a short transient time, at approximately $507.6 \mathrm{~V}$.

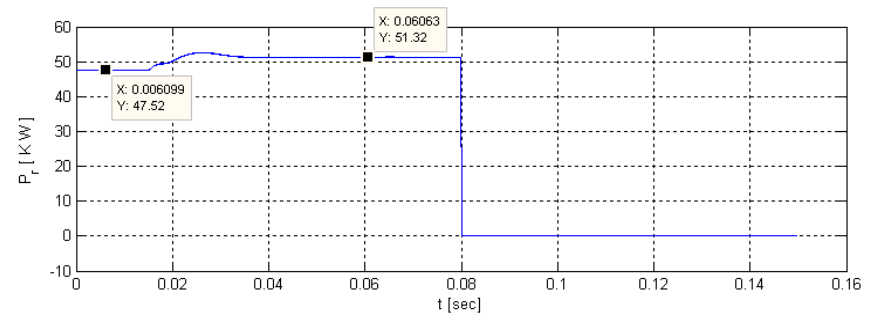

Fig. 19. Time variation of electric power absorbed by resistive load.

Variation in time of electric power absorbed by resistive load is presented in Figure 19, from which it is observed that the role of MPPT regulator is to adapt power generated by photovoltaic park $P_{s f}=51.32 \mathrm{~kW}$, as close as possible to consumer power $P_{c}=51.32 \mathrm{~kW}$ (first maximum power point).

\section{प्Conclusions}

Continuous evolution of humanity is closely related to consumption of electricity, with development of society (increasing dependence on comfort), has led to both increased pollution and declining sources of fossil fuels. Under these limiting conditions, priorities of energy stability policies are represented by energy efficiency and environmental protection. A solution to related issues is to increase generation of energy from renewable sources, where the sun is a clean source of inexhaustible energy.

Paper makes a constructive and functional classification of photovoltaic systems, components of these systems, this are modelled and simulated and results of simulations show limits but especially offer possibility of choosing the optimal solution for an energy production park based on solar radiation. Simulation programs, presented in this article can be applied for more complex photovoltaic systems, being of real use for those interested in this field in order to design such photovoltaic systems.

\section{References}

1. M.S. Nan et al, MATEC Web of Conferences 290, (2019)

2. MATLAB and Simulink Examples Available on https://www.mathworks.com/academia/ examples.html

3. TS-M400 Datasheet Available on https://www.enfsolar.com/pv/paneldatasheet/crystalline/10501

4. O. Stoicuta et al, Photovoltaic systems (Universitas, Petrosani, 2020)

5. N. Diaconu, M.S. Nan, O. Stoicuta, Industria Textila, 68, 4 (2017)

6. Yu Miao et al, Energies 2019, 12, 1074 (2019)

7. Wenbing Yin et al, 2nd International Conference on Electrical, Control and Automation Engineering (ECAE 2017), Advances in Engineering Research, 140, 108-113 (2017)

8. V. Rudnik et al, MATEC Web of Conferences 141, (2017)

9. R.A. Ufa et al, MATEC Web of Conferences 19, (2014)

10. Z. Hongxia et al, MATEC Web of Conferences 108, (2017)

11. Z. Li, MATEC Web of Conferences 59, (2016)

12. H. Yatimi, E., MATEC Web of Conferences 11, (2014)

13. A. El Aroudi et al, MATEC Web of Conferences 16, (2014) 